\title{
Llançament de coets de paper propulsats amb alumnes de primària
}

\author{
María Isabel Hernández Rodríguez (mariaisabel.hernandez@uab.cat) \\ Víctor López Simó (victor.lopez@uab.cat) \\ Centre de Recerca per a l'Educació Científica i Matemàtica (CRECIM). Universitat Autònoma de Barcelona.
}

En aquest article presentem una activitat realitzada durant els anys 2013 i 2014, en el marc del projecte CROMA amb estudiants de cicle mitjà i superior d'educació primària. En aquesta activitat s'ha utilitzat una llançadora d'aire comprimit per propulsar coets de paper fets per nens $i$ nenes de 9 a 11 anys, la qual cosa els ha permès realitzar un estudi dels factors que intervenen en que l'abast del coet sigui major o menor. L'article descriu el material utilitzat, l'estructura de l'activitat i les valoracions documentades a partir de les intervencions realitzades.

Paraules clau: coets de paper, llançadora, educació primària.

In this paper we present a teaching activity carried out in 2013 and 2014, within the framework of the CROMA project with primary school students (Grades 3-6). In this teaching activity a compressed air rocket launcher was used to propel paper rockets built by 9 11 year-old pupils. Building and launching their own paper rockets allow them to analyze factors that affect the scope the rocket reaches. The paper describes the material used to build and launch the rockets, the structure of the teaching activity and its evaluation documented from the enactments carried out.

Key words: paper rockets, launcher, primary

\section{INTRODUCCIÓ}

Els coets són vehicles que permeten posar satèl-lits en òrbita, llençar sondes espacials que escapin de l'òrbita terrestre o enviar naus tripulades a l'espai. Malauradament, aquests aparells també tenen usos militars.

Aquests aparells tecnològics han estat utilitzats des de fa dècades en contextos escolars, ja que el procés de llançament d'un projectil no només pot ser molt divertit i estimulant per als infants, sinó que permet aprofundir en alguns conceptes científics: trajectòries, velocitats, forces, canvis de pressió, canvis químics -si es donen-, transferència d'energia, gravitació, sistema solar, etc. En números anteriors d'aquesta mateixa revista ja s'han presentat algunes activitats consistents en analitzar la trajectòria parabòlica d'un coet disparat utilitzant aigua a propulsió amb alumnes d'ESO i Batxillerat (Martínez, 2008; Torres i Martínez, 2013;), i són nombroses les publicacions que proposen i donen indicacions sobre com fabricar i disparar coets com a activitat didàctica (Schertle, 2010; Shearer i Vogt, 2011).

En aquest article presentem una activitat de 2 hores de durada realitzada durant els anys 2013 i 2014, en el marc del projecte CROMA[1] amb estudiants de cicle mitjà i superior d'educació primària. En aquesta activitat s'ha utilitzat una llançadora d'aire comprimit per propulsar coets de paper fets per nens i nenes de 9 a 11 anys, la qual cosa els ha permès realitzar un estudi dels factors que intervenen en que l'abast del coet sigui major o menor. 


\section{La llançadora d'aire comprimit}

L'element tècnic central necessari per fer aquesta activitat és una llançadora d'aire comprimit. Aquesta llançadora consta d'un conjunt de tubs de coure limitats per una entrada i una sortida d'aire. L'entrada és una vàlvula de roda de bicicleta que permet introduir aire a pressió amb una manxa i mantenir-lo dins. La sortida és una clau de pas, seguida d'un connector a un tub de plàstic obert, que permet la sortida a pressió de l'aire quan s'obre la clau. D'aquesta manera, per fer funcionar la llançadora, primer s'introdueix l'aire a pressió (a 2 o 3 atmosferes), i tot seguit s'obre la clau de pas i tot l'aire surt de cop. La llançadora consta també d'un canó de projecció que es pot orientar en diferents angles per tal que el coet surti disparat amb una inclinació determinada. Un sistema com el que es descriu va ser construït en el marc de les jornades de formació anomenades "Stimulating Physics Network" i organitzades pel "Institute of Physics" de Londres [2], a les quals van assistir els autors l'any 2010.

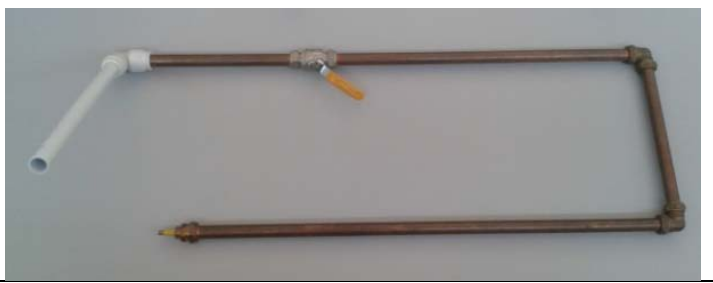

Figura 1. Imatge de les parts de la llançadora.

\section{Els coets de paper}

Els coets que poden ser propulsats amb aquesta llançadora estan formats per tres parts: el tronc en forma de cilindre, l'ogiva en forma de con, i els alerons de forma triangular. Per construir aquests coets, tan sols cal paper o cartolina, cinta adhesiva i tisores. A més, cada infant pot decorar el seu coet amb retoladors o gomets.
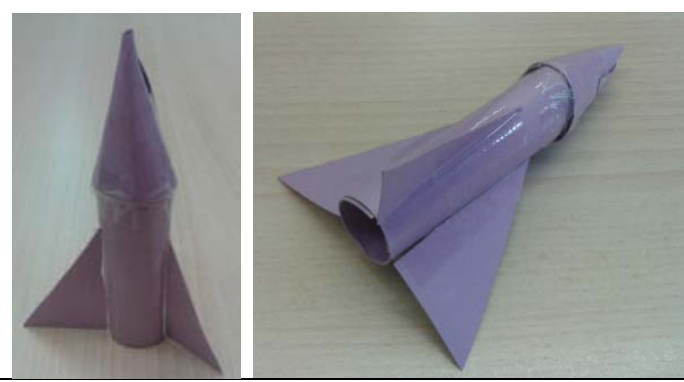

Figura 2. Imatges de les parts del coet.

\section{DESCRIPCIÓ DE L'ACTIVITAT}

Aquesta activitat comença amb una presentació d'un context realista com ara el següent:

Per un dia serem enginyers d'una agència espacial (com l'ESA o la NASA) encarregats del disseny i construcció d'un coet que haurà de ser aerodinàmic i estable per tal que arribi el més lluny possible (abast). Cada equip haurà de construir el seu coet, provarem de llançar-lo i compararem les característiques de cada coet en funció de l'abast màxim que hagin assolit.

A partir d'aquí, ens endinsem en l'exploració d'idees prèvies dels alumnes a partir de la pregunta "Com creieu que ha de ser el coet que construïm per tal que arribi el més lluny possible?" Algunes de les respostes més comunes dels alumnes són:

- Ha d'acabar en punta per ser més aerodinàmic

- Ha de tenir alerons per ser estable i evitar que pateixi turbulències

- Ha de ser lleuger per poder sortir disparat amb molta velocitat

- Ha de ser impulsat el més fort que es pugui (amb aire, deixant anar un globus, fent pressió, etc.)

Altres factors com la llargada del coet o el material del que està fet porten més controvèrsia a l'hora de predir com es comportarà el coet que construeixin.

Un cop discutits aquests factors, es presenta un coet fet pels professors, i també el sistema que s'utilitzarà per disparar-lo. Després, es col-loca aquest coet a la llançadora i es dispara, com a estímul pels infants i per presentar la metodologia de realització de proves que es farà posteriorment.

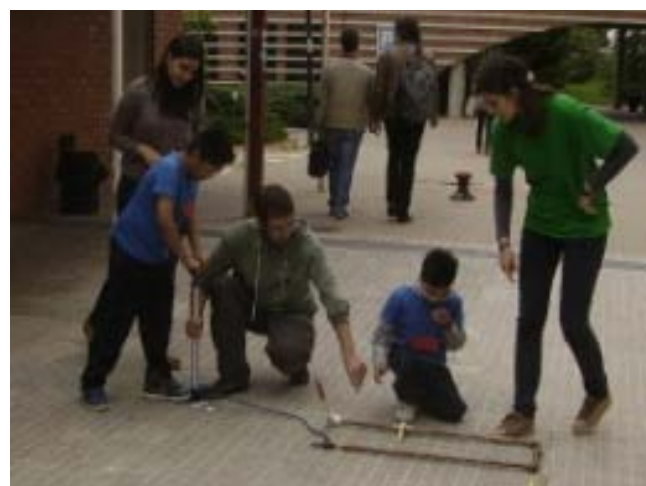

Figura 3. Imatge de l'explicació de com funciona la llançadora. Es veu un infant introduint aire a través de la manxa. 
En paral-lel, també cal explicar el procediment per construir els coets. Al fer-ho, es pot aprofitar per discutir amb els infants de quantes parts està format el coet i quines formes geomètriques tenen aquestes parts, aprofitant així per relacionar l'àrea de ciències i de matemàtiques. Amb al procediment aclarit, es passa a la fabricació dels coets. Per construir el cilindre del cos del coet, és important que els alumnes ja prenguin com a referència de diàmetre el canó de la llançadora per tal d'evitar que els facin massa estrets o amples. Per construir el con de la punta del coet també és important que tapin qualsevol forat amb celo per evitar que s'escapi l'aire.

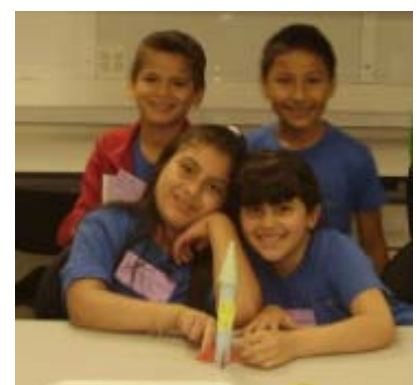

Figura 4. Grup d'infants amb el coet que han fabricat.

Finalment, amb els coets construïts, cada grup d'infants ja pot disparar el seu coet, activitat que és recomanable fer a l'exterior, ja que els coets poden sortir a més de 15 metres d'abast i més de 3 metres d'alçada, depenent del propi coet i de la inclinació del canó de projecció de la llançadora. Per tal de controlar la resta de variables que poden afectar a la mesura, s'explicita que tant la pressió d'aire com la inclinació del canó han de ser les mateixes per a tots els llançaments. Per mesurar l'abast de cada coet es pot fer servir una cinta mètrica, i per recollir aquests valors és convenient anar apuntant els resultats experimentals en forma de taula. D'aquesta manera, cada equip podrà llençar el seu coet i anotar a la taula la distància a la qual ha arribat. A més, cada grup pot fer diversos llançaments de cada coet (sobretot si fa vent) i calcular el valor mitjà.

Amb la taula feta, es passa a la discussió en gran grup dels resultats i conclusions, seleccionant el coet que ha arribat més lluny. S'analitzen les característiques d'aquest coet en comparació amb els altres. Es pot arribar a la conclusió de que algunes de les condicions òptimes per fer arribar el coet més lluny són:

- Que el coet sigui més curt que no pas llarg (al voltant dels $10-15 \mathrm{~cm})$. D'aquesta manera, serà més lleuger i estable.

- Que els alerons tampoc siguin gaire grans ni estiguin arrugats, per tal que la forma sigui el més aerodinàmica possible.

- Que tingui un pes adequat per ser lleuger però al mateix temps que no el desviï el vent fàcilment. Per això va millor que estigui fet de cartolina que no pas de paper.

- Que la punta estigui centrada i no desviada.

\section{VALORACIÓ DE L'ACTIVITAT}

Les dues ocasions en que s'ha fet aquesta activitat la valoració feta tant pels mestres com pels infants és molt positiva, degut a diversos motius. D'una banda, són els propis infants els que dissenyen i construeixen el seu propi coet basant-se en una hipòtesi (La forma i els materials de cadascuna de les parts que constitueixen un coet de paper afecten al seu abast en un llançament). Posteriorment també són ells mateixos els que poden comprovar les seves hipòtesis realitzant el llançament. L'activitat combina un treball experimental en ciències (control de variables, elaboració de prediccions, recollida i comparació de resultats, etc.) amb activitats d'altres àrees (plàstica i matemàtiques). A més, és una oportunitat d'aprenentatge per abordar alguns dels conceptes científics de la mecànica i el moviment (com varia la velocitat del coet al llarg del seu recorregut?), i també del model de matèria que permet explicar la pressió de l'aire a l'interior de la llançadora.

\section{BIBLIOGRAFIA}

MARTÍNEZ ESPINET, B. (2008). Anàlisi del moviment de coets d'aigua. Ciències: revista del professorat de ciències de primària $i$ secundària, 11 , p. $2-7$

SCHERTLE, R. (2010). Compressed air rocked. Makezine, 15, p.102-113.

DEBORAH A, SHEARER, M.S:, GREGORY, L. I VOGT, Ed.D. (2011). ROCKETS. Educator's Guide with Activities in Science, Technology, Engineering and Mathematics. NASA

TORRES CLIMENT, À.L., MARTÍNEZ SEMPERE, T.J. (2013) Construcció i aprofitament didàctic del coet d'aigua. Ciències : revista del professorat de ciències de primària $i$ secundària, 26, $p$. $16-20$

[1]http://www.uab.cat/web/programessocials/croma/missio-i-beneficiaris1274251159099.html

[2]http://www.iop.org/education/teacher/support/net work/cpd-sessions/page_44093.html 